\title{
Using a rapid assessment approach to evaluate the quality of care in an integrated program: The experience of the Family Health Division, Ministry of Health, Botswana
}

Lucy Sejo Maribe

Baker Ndugga Maggwa

Population Council

Ian Askew

Population Council

Kate Miller

Population Council

Follow this and additional works at: https://knowledgecommons.popcouncil.org/departments_sbsr-rh

Part of the Health Services Research Commons, International Public Health Commons, and the Quality Improvement Commons

How does access to this work benefit you? Let us know!

\section{Recommended Citation}

Maribe, Lucy Sejo, Baker Ndugga Maggwa, lan Askew, and Kate Miller. 1997. "Using a rapid assessment approach to evaluate the quality of care in an integrated program: The experience of the Family Health Division, Ministry of Health, Botswana," Africa OR/TA Project II Final Report. Nairobi: Population Council. 
November 1997
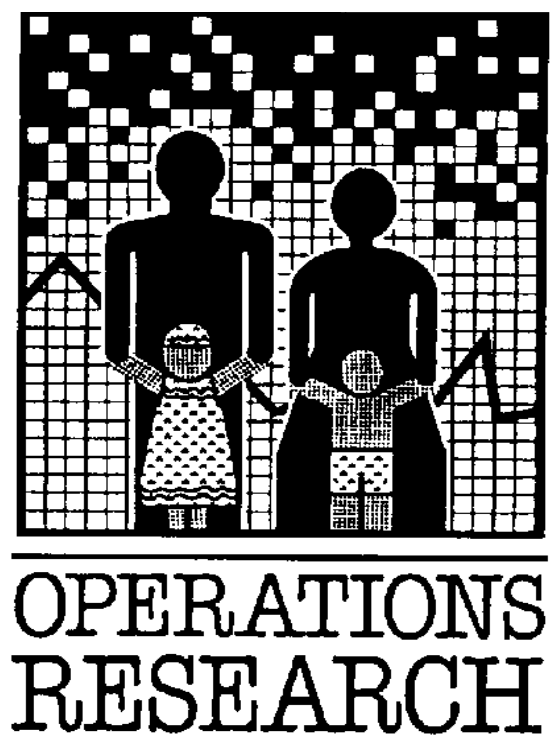

TECHNICAL ASSISTANCE

AFRICA PROJECT II

THE POPULATION COUNCIL

Using a Rapid Assessment Approach to Evaluate the Quality of Care In an Integrated Program:

The Experience of the Family Health Division, Ministry of Health, Botswana. 


\section{The Population Council}

\section{The Population Council}

The Population Council seeks to help improve the well-being and reproductive health of current and future generations around the world and to help achieve a humane, equitable, and sustainable balance between people and resources. The Council analyzes population issues and trends; conducts biomedical research to develop new contraceptives; works with public and private agencies to improve the quality and outreach of family planning and reproductive health services; helps governments to influence demographic behavior; communicates the results of research in the population field to appropriate audiences; and helps build research capacities in developing countries. The Council, a nonprofit, nongovernmental research organization established in 1952, has a multinational Board of Trustees; its New York headquarters supports a global network of regional and country offices.

\section{Africa OR/TA Project II}

The overall objective of the Africa OR/TA Project II is to broaden understanding of how to improve family planning services in Sub-Saharan Africa, and to apply operations research and technical assistance to improve services by:

C increasing access to a full range of family planning services and methods;

C developing service delivery strategies that are client-oriented and acceptable to various population groups;

C improving the operations of programs to make them more efficient and financially sustainable;

C improving the quality of services;

C strengthening the capabilities of family planning program managers to use operations research to diagnose and solve service delivery problems.

This project was supported by the Population Council?s Operations Research and Technical Assistance Project II, Project No. 936-3030, and by the Population Council?s Cooperative Agreement No. CCP-3050-A-00-4013-00, both funded by the United States Agency for International Development (USAID). 


\section{TABLE OF CONTENTS}

ACKNOWLEDGEMENTS I

EXECUTIVE SUMMARY III

$\begin{array}{ll}\text { I. BACKGROUND } & 1\end{array}$

II. STRENGTHENING PUBLIC SECTOR REPRODUCTIVE HEALTH SERVICES 2

i) In-service Training of MCH/FP Service Providers 2

ii) Strengthening the Management Information System $\quad 3$

iii) Strengthening IEC activities for family planning and STI prevention $\quad 4$

iv) Strengthening research, evaluation and monitoring activities 4

III. AN APPROACH FOR THE RAPID ASSESSMENT OF SERVICE QUALITY 5

$\begin{array}{lr}\text { i) Indicators for monitoring program performance } & 5\end{array}$

ii) A mechanism for collecting data and measuring the indicators $\quad 7$

iii) Field testing the rapid assessment mechanism $r$

$\begin{array}{lr}\text { IV. RESULTS } & 12\end{array}$

i) Readiness of facilities to provide quality services 12

ii) Quality of services provided $\quad 16$

$\begin{array}{ll}\text { V. SUMMARY OF KEY RESULTS } & 23\end{array}$

i). Readiness of facilities to provide quality services:

ii). Quality of Services Provided 23

$\begin{array}{lr}\text { VI. USE OF RESULTS } & 24\end{array}$

$\begin{array}{ll}\text { APPENDIX 1 LIST OF INDICATORS } & 25\end{array}$

APPENDIX 2 PRINCIPLES OF LOT QUALITY ASSURANCE SAMPLING 28

APPENDIX 3 HEALTH FACILITIES VISITED 30 


\section{ACKNOWLEDGEMENTS}

In preparing for and developing this rapid assessment mechanism, the $\mathrm{MCH} / \mathrm{FP}$ unit and The Population Council OR/TA project staff worked very closely with members of other units of the Family Health Division, the District Health Teams, UNFPA, UNICEF, the Health Research Unit at the Ministry of Health and the Department of Primary Health Care at the Ministry of Local Government. Special thanks go to all the staff from these organizations who helped with the development and review of the summary program performance indicators, mechanism and instruments for collecting data and measuring these summary indicators. At the clinics which participated, our special thanks go to the clinic staff and clients for the cooperation and assistance they extended to the study teams.

Special mention must be made of Mr. Scott Stewart, the Health, Population and Nutrition Advisor at the USAID Mission in Botswana at the time of this activity for the timely administrative and logistic support he provided to the study team. The field work would not have been possible without the participation of the BOTSPA project zonal supervisors, members of the training resource group and staff of the Central Training Section. Their role in the study is gratefully acknowledged. Mentioning everybody who contributed to the success of this activity is not possible but their roles are acknowledged. 


\section{Executive Summary}

To strengthen existing efforts by the Government of Botswana in responding to the HIV/AIDS epidemic, USAID provided financial and technical assistance through the Botswana Population Assistance (BOTSPA) project. The overall goal for the BOTSPA project was to improve the quality and availability of family planning and STI services through designing, implementing and monitoring activities that would lead to the eventual institutionalization and sustainability of high quality family planning and STD/HIV/AIDS services. The following activities were developed and implemented by the Family Health Division of the Ministry of Health under the BOTSPA project with technical assistance from the Cambridge Consulting Consortium:

- In-service training of $\mathrm{MCH} / \mathrm{FP}$ service providers

- Strengthening the management information system (MIS) of the MCH/FP program

- Strengthening IEC activities for family planning and STI/HIV prevention

- Implementation of research, evaluation and monitoring activities.

Although each of these interventions included their own assessment activities, the assessments were primarily of the outputs produced by the interventions themselves. However, the BOTSPA project itself did not include strategies for measuring the broader impact of its activities. Thus it was not possible to know whether the Project was contributing to its overall purpose or whether it was having an effect on the quality and availability of services, and consequently on fertility regulating behavior and the incidence of STDs and HIV.

Consequently, there was need to develop a rapid but cost-effective approach to routinely monitor the quality of services provided to clients. The MOH had experimented previously with indepth supervisory visits as one approach to doing this, but wanted to develop a systematic and sustainable approach to regularly measure service quality which could be incorporated into its overall MIS. The MOH requested assistance from the Africa OR/TA Project II through USAID/Botswana to develop and test an approach for routinely measuring the quality of service delivery and for assessing the retention of skills by staff trained through the in-service courses. Following consultations between the MOH and the Africa OR/TA Project II, the following threestep process was designed:

- develop indicators for monitoring program performance

- develop a mechanism for collecting data and measuring the summary indicators

- field test the rapid assessment mechanism.

A rapid assessment mechanism that utilizes the Lot Quality Assurance Sampling (see Appendix 2) technique was developed and field tested using the BOTSPA project zonal supervisors and members of the training resource group. This rapid assessment mechanism was then used to determine the readiness of health facilities in Botswana to offer quality family planning and STI management services following activities implemented under the BOTSPA Project and to evaluate the quality of services provided by providers who had been trained through the project. 
Overall the mechanism was found to be generally acceptable, easy to use by staff and managers, and provided valid information on the readiness of the health facilities to provide family planning and STI services. The mechanism was also found to be useful in identifying specific areas that needed attention at both the health facility and service provider levels.

\section{Readiness of facilities to provide quality services:}

- Basic infrastructure is present, although attention needs to be paid to ensuring that separate counseling / examination rooms are available at all facilities to safeguard privacy during client / provider interactions.

- Basic equipment, supplies and infection control facilities are almost universally available.

- Although clinic registers and the drug store books were available at most facilities, they were not well completed, not legible and did not have up-to-date information.

- Apart from the low dose combined oral contraceptive pill found to be missing at several health facilities, other commonly used contraceptive commodities were generally available.

- Flip-charts which are important for informing, educating and communicating with clients about family planning and STIs were lacking in most facilities.

- Despite the official expectation, family planning, STI and HIV/AIDS services were not being provided to clients after 1.45 p.m. Also few facilities had signs announcing the availability of family planning, STI and HIV/AIDS services at the facilities.

\section{Quality of Services Provided}

- Although most of service providers were performing all the clinical procedures required for new family planning clients many were found to lack adequate skills when performing general and breast examinations, STD/AIDS risk assessment and counseling for clients

- Staff were not carrying out STD/AIDS risk assessment and counseling for clients as is required by the guidelines.

- Counseling provided by staff did not have a major impact on the knowledge of symptoms for STDs among clients

\section{Use of results:}

The MCH/FP unit has utilized this information to more accurately define areas in their program that need to be addressed. For example BOTSPA trainers have used these results to revise their training curriculum to put more emphasis on general and breast examination procedures, STD and HIV/AIDS risk assessment and counseling areas identified as requiring improvement by this exercise. The MCH/FP unit revised its family planning client record forms to facilitate the recording of information required to measure some of the indicators. The information has also been used in training workshops for supervisors in the District Health Teams and in the development of 
checklists for these supervisors. Many of the indicators defined in this study have also been incooperated in the Ministry of Health Information System for use at a national level. 


\section{Background}

Rates of infection with the Human Immune-deficiency Virus (HIV) have continued to rise rapidly in Sub-Saharan Africa despite efforts undertaken by governments and international agencies. In Botswana, the number of persons with HIV infection rose from 60,000 to 190,000 between 1992 and 1995. Among pregnant women, the infection rates increased from 22.5 percent to 32.5 percent over the same period. Moreover, in 1993 HIV prevalence among pregnant women was higher in the urban $(22.5 \%)$ than rural $(16.1 \%)$ populations but by 1995 this gap had nearly disappeared ${ }^{1}$.

Service statistics for the period 1988-1991 showed a 26 percent rise in the number of patients treated for sexually transmitted infections (STIs) in government clinics ${ }^{2}$. Data from the Botswana HIV sentinel surveillance have shown that HIV infection rates are higher among clients with STIs than those without by a factor of 30 percent, a finding in agreement with observations from other countries in the region which suggest a causal relationship between some STIs and HIV infection $^{3}$.

A study in Mwanza, Tanzania demonstrated a 40 percent reduction in the incidence of HIV infection following a campaign to detect and treat STIs in the community ${ }^{4}$. The results from this study have inspired many programs and donors in the region to develop new and strengthen existing STI control activities with the hope of slowing down HIV transmission.

Besides contributing to a reduction in the HIV epidemic, detecting and managing STIs in itself is an important public health activity given the high prevalence of these infections in Botswana and throughout the region. If left untreated STIs are associated with severe complications, especially for women and unborn children. Moreover, as with most of the countries in the region, Botswana is a signatory to the ICPD (Cairo, 1994) and Beijing (1995) declarations that call for a comprehensive approach to the provision of reproductive health services for women. The Ministry of Health in Botswana has been at the fore front of developing and implementing strategies in response to these local and global needs.

1 Data from the National Sentinel surveillance, National AIDS Control Program, Ministry of Health, Gaborone, Botswana, 1996.

Central Statistics Office (1993). State. Brief: Health Statistics 1987-1992, Central Statistics Office Gaborone, Botswana

Plummer FJ, Simonsen D Cameron et al. (1991). "Co-factors in male- female sexual transmission of Human Immunodeficiency Virus Type 1" Journal of Infectious Diseases, 163:233-239; Laga M, (1992). " Human immunodeficiency Virus Prevention: The need for Complementary Sexually Transmitted Disease Control", pp 131-144 in Germain A, Holmes K, Piot P and Wasserheit J (eds) Reproductive Tract Infections: Global Impact and Priorities for Women's Reproductive Health. Plenum Press New York, NY USA; Hunter D, Maggwa BN, Mati J., et al. (1994). "Sexual Behavior, Sexually Transmitted Diseases, Male Circumcision and Risk of HIV infection among women in Nairobi, Kenya", AIDS, 8:93-99; Kapiga S, Shao J, Lwihula G and Hunter D (1994). "Risk factors for HIV among women in Dar es Salam, Tanzania", Journal of Acquired Immune Deficiency Syndrome, 7:301-309. 


\section{Strengthening Public Sector Reproductive Health Services}

In response to these challenges, the Government of Botswana established a National AIDS Control Program (NACP) to guide a multi-sectoral response to the HIV/AIDS epidemic and STIs. Through the AIDS/STD Unit at the Ministry of Health, the NACP undertakes the following activities:

- Sentinel surveillance surveys

- Prevention of sexual transmission of HIV through IEC activities, control of STIs and condom promotion.

- Screening of blood and other products

- Care of persons with HIV infection including clinical management of complications, home based care support and counseling of families of persons with HIV infection

In 1992 the AIDS/STD Unit adopted the syndromic approach to detect and manage STIs. This required the development of new service provider guidelines and treatment algorithms, training nurses and nurse-midwives in this approach, and ensuring the availability of drugs for treating STI syndromes. However, subsequent program reviews found that women receiving $\mathrm{MCH} / \mathrm{FP}$ services were not receiving STI services.

To overcome this problem and strengthen existing efforts, USAID provided financial and technical assistance to the Government of Botswana through the Botswana Population Assistance (BOTSPA) Project. The overall goal for the BOTSPA Project was to improve the quality and availability of family planning and STI services through designing, implementing and monitoring activities that would lead to the eventual institutionalization and sustainability of high quality family planning and STD/HIV/AIDS services. The following activities were developed and implemented by the Family Health Division of the Ministry of Health under the BOTSPA Project with technical assistance from the Cambridge Consulting Consortium:

- In-service training of MCH/FP service providers

- Strengthening the management information system (MIS) of the MCH/FP program

- Strengthening IEC activities for family planning and STI/HIV prevention

- Implementation of research, evaluation and monitoring activities.

\section{i) In-service Training of MCH/FP Service Providers}

As part of the BOTSPA Project, a Central Training Section (CTS) was created in the Family Health Division and mandated to develop an in-service training curriculum in FP/STI delivery and counseling skills, IEC activities and MIS for nurses and family welfare educators. By the end of 1994, a training curriculum and training schedule had been developed. The target was to train 305 staff including nurse midwives and family welfare educators. 
Training of trainers: A training resource group (TRG) consisting of 31 experienced nurse midwives was created and trained as master trainers. The country was divided into four project zones and members of the TRG were selected to train and supervise service providers within these zones.

Training of service providers: The BOTSPA project created "centers of competence" by training teams of service providers consisting of a senior nurse midwife, one other nurse midwife and one or two family welfare educators for a selected number of facilities in each zone. By 1996, 73 nurse midwives, 15 IEC promoters and 155 family welfare educators providing services at 53 health facilities had attended the four-week BOTSPA in-service training course which included:

- Updates on family planning, STIs and HIV/AIDS

- Counseling and communication skills

- Management Information System

- Use of the Family Planning general policy guidelines, service standards and procedure manuals.

\section{ii) Strengthening the Management Information System}

A review of the first phase of the BOTSPA Project in 1991 found that service statistics collected by the $\mathrm{MCH} / \mathrm{FP}$ program were of poor quality, untimely and seldom used for program management. To address these concerns, the second phase of the BOTSPA Project included training $\mathrm{MCH} / \mathrm{FP}$ service providers in MIS techniques, revision and distribution of the existing family planning logistics manual, and compilation of a family planning MIS reference guide.

Training MCH/FP service providers in MIS: The goal was to train 305 service providers in MIS/logistics as well as familiarizing 105 FP/STI program supervisors with the MIS. By 1996, all 30 TRG members and the 73 nurse/midwives who had attended the in-service training courses had been trained in MIS/logistics using a draft curriculum developed by the Family Health Division. At the end of the training in MIS, staff were expected to:

- use the revised family planning MIS reporting forms that would include space for recording STD information to collect accurate client information,

- analyze routine data and asses progress based on the established indicators,

- identify trends in data based on the analysis carried out at each health facility

- define and take programmatic actions based on data analysis.

Revision and distribution of a family planning logistics manual: The MOH has had a logistics manual since 1989. This manual was to be revised as part of the BOTSPA II but this activity was not completed.

Compilation of a family planning MIS reference guide: This was to be used as reference by service providers at the health facility level. The manual had not been finalized at the time this study was carried out. 


\section{iii) Strengthening IEC activities for family planning and STI prevention}

The first phase of the BOTSPA Project included many IEC activities in support of the $\mathrm{MCH} / \mathrm{FP}$ program: short and long term training for $\mathrm{MOH}$ staff; family life education workshops for NGOs; purchase of equipment for print and radio production of IEC materials; and production of IEC materials and distribution. A 1994 review found there were sufficient IEC materials on family planning and STI prevention for the formulation and implementation of an IEC strategy; however, the materials had not been well distributed and were not being used by the service providers. Consequently, a training of trainers and three-week training courses in IEC for nurses and FWEs was added to the BOTSPA Project in 1994. The training emphasizes appropriate use of IEC materials during group health talks and counseling individual clients.

\section{iv) Strengthening research, evaluation and monitoring activities}

Although each of these interventions included their own assessment activities, the assessments were primarily of the outputs produced by the interventions themselves. However, the BOTSPA project itself did not include strategies for measuring the broader impact of its activities. Thus it was not possible to know whether the Project had contributed to its overall purpose or whether it had an effect on the quality and availability of services, and consequently on fertility regulating behavior and the incidence of STDs and HIV.

Strengthening the MCH/FP MIS was intended to facilitate the measurement and reporting of conventional indicators of the quantitative aspects of FP/STI service delivery, for example, numbers of new and repeat FP users, supplies distributed, couple-years of protection (CYP), contraceptive prevalence, and numbers and types of STI treated. The MIS does not, however, permit indicators of the quality of service provided and retention of skills by staff trained to be measured and reported. 


\section{An Approach for the Rapid Assessment of Service Quality}

Following completion of the national Situation Analysis study in $1995^{5}$, the Botswana MOH felt that the information collected through this approach was useful for assessing the quality of services provided through its newly integrated MCH/FP/STI/HIV program. However, the MOH wanted to be able to measure the quality of care provided on an annual or biannual basis, and clearly the Situation Analysis approach was not appropriate given the scale and cost of implementing such studies.

Prior to the Situation Analysis study, the MOH had experimented with in-depth supervisory visits as one approach to doing this, but wanted to develop a systematic and sustainable approach to regularly measure service quality which could be incorporated into its overall MIS. Consequently, the $\mathrm{MOH}$ requested assistance from the Africa OR/TA Project II through USAID/Botswana to develop and test an approach for routinely measuring the quality of service delivery and for assessing the retention of skills by staff trained through the in-service courses. Following consultations between the $\mathrm{MOH}$ and the Africa OR/TA Project II, the following three-step process was designed:

- develop indicators for monitoring program performance

- develop a mechanism for collecting data and measuring the summary indicators

- field test the rapid assessment mechanism.

\section{i) Indicators for monitoring program performance}

A one week workshop was organized by the MOH Family Health Division, with technical assistance from the Africa OR/TA II Project, to develop indicators which they felt would be useful in assessing service quality. Participants were drawn from various sectors of the Ministry of Health, Ministry of Local Government and donors involved in the provision of reproductive health services in the country. The workshop was divided into four sessions to allow participants to systematically develop the indicators. During each session, relevant background papers were presented by the Family Health Division, the Health Statistics Unit, the AIDS/STD Unit, the Africa OR/TA Project II, and UNFPA. These presentations were used to update participants on monitoring and evaluation of reproductive health programs and to inform them about existing program strategies and management information systems.

After each presentation participants were divided into smaller working groups for in-depth discussions. Proceedings from the working groups were presented, discussed and consensus obtained during plenary sessions. During the workshop participants developed a mission statement, identified key program elements they wished to assess, and defined indicators to measure these elements.

$5 \quad$ Baakile, B., L. Maribe, B. N. Maggwa \& R. Miller. A Situation Analysis of the Maternal and Child Health / Family Planning (MCH/FP) Program in Botswana, Botswana Ministry of Health and the Africa OR/TA Project, The Population Council, Nairobi, Kenya. 1996. 
Mission Statement: The main purpose for developing a mission statement was to achieve a common understanding of the program and a mutually agreed upon reference point that would guide the development of indicators. To facilitate this exercise, participants were updated on the goals, objectives, strategies and activities of the MCH/FP and AIDS/STI programs, and of the BOTSPA project. The UNFPA country reproductive health strategy and its relationship with these programs was presented. The following mission statement was agreed upon;

"The mission of the Botswana reproductive health program is to help individuals and couples meet their reproductive health intentions by providing timely, accessible, and acceptable family planning and STD/HIV services in a client/provider friendly environment using technically competent staff."

Identification of program elements: Using the mission statement, participants were asked to define those program elements which are essential for achieving the goals in the mission statement and which they would like to monitor. To assist with this exercise, participants were updated on current concepts in quality of care and frameworks for reproductive health program assessment. The following list of program elements was defined and agreed upon:

- Physical infrastructure preparedness

- Accessibility of services

- Availability of equipment, supplies, contraceptive commodities and STI drugs

- Good infection control procedures

- Facilitative management and supervision

- Transport and communication facilities

- Staff preparedness

- Supportive policies and documents

- Research and evaluation.

The participants then went further and defined the ingredients of good quality reproductive health services as follows:

- Information given to clients about services sought

- Facilitation of informed choice of contraceptive methods

- Integration of reproductive health services offered to clients

- Interpersonal relationships

- Mechanisms to ensure continuity with services offered

- Identification of client service needs.

Definition of indicators: Participants developed indicators to monitor these program elements and the components of quality of care. To guide this activity participants were informed about the types of information already being collected through the MIS of the MCH/FP and Health Statistics Units in the Ministry of Health. Examples of quality of care indicators from other programs in subSaharan Africa and findings from the Botswana Situation Analysis were presented and discussed. 
Participants were also updated on standard guidelines for developing and identifying indicators.

Working in groups the participants defined 107 indicators they thought would be useful in monitoring the integrated activities of the Family Health Division. During the plenary session, however, it was agreed that these were too many, and a scoring system was used to reduce the number of indicators based on each indicator's validity, reliability, ease of data collection, cost of data collection and usefulness in program planning. A total of 50 indicators that satisfied these criteria were retained (see appendix 1), and these were used in developing the rapid assessment mechanism.

\section{ii) A mechanism for collecting data and measuring the indicators}

The MCH/FP Unit was looking to develop a rapid assessment approach that had low data collection and analysis costs, is easy to train staff in its use, easy to use, requires a short time to complete, and produces results that are easy to interpret and can be used to make managerial decisions at all levels of the health care system.

Although the Situation Analysis approach provides very useful information about programs, it does not meet these criteria because it requires visits to a large sample of clinics and because huge amounts of data are collected, therefore, analysis and interpretation can be time-consuming. Other strategies have been used and found to provide reliable information that can be used for monitoring program performance from fewer facilities and staff. One such strategy is the Lot Quality Assurance Sampling (LQAS) technique which has been developed and applied in the context of health care by Valadez ${ }^{6}$; the technique has been applied recently for assessing the family planning service delivery skills of providers in Kenya ${ }^{7}$.

The "underlying principle [of LQAS] is that to control quality, managers need to determine only whether a specified minimum performance threshold has been reached. By this assessment, rather than by measuring the exact proportion of service providers that perform a service adequately, the standard binomial formula can be used to calculate the sample size" . A full description of the LQAS technique is given in Appendix 2, but essentially this technique is used to help managers make decisions like:

- whether a provider has reached a certain minimum threshold of technical competence, measured by whether a provider is observed to deliver services using the correct techniques at least 95 percent of the time;

- whether a certain minimum proportion of providers in a cohort of trained providers retained the

\footnotetext{
$6 \quad$ Valadez, J. Assessing Child Survival Programs in Developing Countries: Testing Lot Quality Assurance sampling. Department of Population and International Health, Harvard School of Public Health, Boston, 1991.

$7 \quad$ Valadez, J. et al. “Assessing family planning service-delivery skills in Kenya”, Studies in Family Planning, 28,2:143-150. 1997.

$8 \quad$ Valadez, J., et al. 1997, op cit.
} 
skills acquired in their course; this proportion is usually 80 percent.

- Whether a certain minimum proportion of health facilities is prepared to provide good quality services.

It was felt that this approach could be adapted to meet most of the managers' criteria for assessing quality, in terms of provider competence, the readiness of facilities to offer quality, integrated services, and the quality of services received by clients. A decision was taken to develop and field test a rapid assessment mechanism based on LQAS technique and using the indicators identified.

Sampling framework: In designing the sampling frame, the following constraints were considered.

- The field test exercise had to start in June and be completed before mid- August, 1996 due to the requirement that all USAID-funded activities in Botswana had to be completed by September 31, 1996.

- The Family Health Division chose to utilize the members of the TRG for implementing the field test as they would be responsible for monitoring the program in the future. These trainers are full-time employees at the health facilities with other responsibilities and so could only be available for short periods of time.

- Although the BOTSPA Project had trained over two hundred staff, many facilities have only one staff member who has been trained. In addition some of the trained staff have been transferred from their original facilities making it difficult for their impact to be measured. This leaves only a few facilities with the complete teams which the BOTSPA Project had intended to create as "centers of competence".

A two stage sampling design was developed. First a sample size for facilities was calculated to enable the study to determine whether an acceptable proportion of facilities was adequately prepared to provide integrated reproductive health services. Second, a sample size for the cohort of providers trained through the BOTSPA Project was calculated to determine whether an acceptable proportion of these providers was delivering services using the skills in which they were trained.

Sample size of health facilities: Only those health facilities with at least one BOTSPA-trained nurse midwife who had been at that health facility since their training for not less than three months were included in the study. Although nurses from 53 health facilities had been trained, only 40 facilities had nurses who had remained for at least three months, and so these 40 facilities were considered as the cohort from which the sample was randomly selected.

Decision rules were established for whether or not a health facility could be judged as providing quality services. Each health facility was assigned a "pass" or "fail" for the indicators used to assess its preparedness to provide good quality integrated family planning and STI services. The $\mathrm{MCH} / \mathrm{FP}$ Unit stated that it would be willing to accept the program as successful if 80 percent of the facilities with a BOTSPA trained nurse who remained for more than three months scored a "pass" on each of these indicators, and unsuccessful if $50 \%$ or fewer of these facilities scored a "pass" on each indicator. They were also willing to accept an $\alpha$ error (passing a facility that actually fails the 
test) and a $\beta$ error (failing a facility that actually passes the test) of up to five percent each when classifying the facilities ${ }^{9}$.

Using the binomial formula ${ }^{10}$ described in Appendix 2 and these decision rules set by the MCH/FP Unit, a minimum sample size of 23 health facilities was required. Consequently, 23 facilities were randomly selected from the cohort of 40 facilities (although the research teams actually visited 25 health facilities); a list of these facilities is given in Appendix 3. Based on the decision rules, if more than eight of the 25 facilities were assigned a "fail" for a particular indicator it could be concluded that less than $50 \%$ of all the facilities in the cohort had passed on that indicator and so the program would be judged to be unprepared for that indicator. Conversely, if eight or less of the sampled facilities were assigned a "fail" on an indicator, it could be concluded that more than 80 percent of the sampled facilities had passed on the particular indicator, and so the program could be judged as prepared for that indicator. The $\alpha$ and $\beta$ errors associated with these decision rules were 0.047 and 0.054 , respectively, giving a specificity of $95.3 \%$ and sensitivity of $94.6 \%$.

Sample size of BOTSPA trainees: At the time of the study, 73 nurses had been trained through the BOTSPA Project. These nurses were considered as the cohort from which a sample would be drawn. The MCH/FP Unit decided that they would be willing to accept that the program has been successful in training competent providers, and therefore providing good quality care, if 80 percent of the BOTSPA trainees scored a "pass" on each of the indicators used to assess their service delivery skills. They would consider the training as having been unsuccessful if 50 percent or fewer BOTSPA trainees were scoring a "pass" on each of these indicators. Again, $\alpha$ and $\beta$ errors of upto five percent each when classifying the cohort of staff were acceptable.

Based on these decision rules and using the binomial formula, a minimum sample size of 25 staff was required. Using this sample size and the decision rules above the cohort was judged as performing well if fewer than 8 staff were observed to carry out the expected tasks for their clients. However, the MCH/FP Unit decided to interview and observe all nurse midwives who had attended a BOTSPA in-service course and who were providing services at the 25 facilities included in the study. Since the facilities had been randomly selected, it was assumed that the service providers at these facilities would represent a random sample of the BOTSPA trainees from the cohort.

These errors have also been referred to as provider and consumer risks. The provider risk is the probability of classifying a cohort of provider/facility as inadequate when in reality they are adequate (i,e 1- probability of detecting providers/facilities with adequate skills/equipment where these indicators are used to judge adequacy). The consumer risk is the probability of classifying a cohort of providers/facilities as adequate when in reality they are not (1- probability of detecting providers/facilities with inadequate skills/equipment where these are used as indicators of adequate performance). The sum of these two risks is called the total classification error.

Some other investigators have used the hypergeometric formula especially when dealing with small finite populations. Although using the hypergeometric formula allows for judgments to be made on upper and lower thresholds with smaller intervals between them than when the binomial formula is used little precision is gained at the expense of potentially adding considerable complexity and error to the LQAS procedure (see op cit. Valdez 1991). The binomial formula was used in this study because the intervals between the lower and upper threshold the Family Health Division decided to use in judging the performance of their program were wide enough to allow for judgments to be made with an acceptable level of sensitivity and specificity. 
Altogether, 38 staff were observed providing family planning services to new and repeat family planning clients at the 25 study clinics. Of the 38 staff 25 were observed providing services to 39 new family planning clients. The performance of these 25 staff was used to judge the overall performance of the cohort on those tasks that they are expected to carry out for all new family planning clients.

According to the Botswana Family Planning General Policy Guidelines and Service Standards (revised 1994) all new family planning clients should :

- be given a brief explanation of the clinic routine and procedures,

- be assessed for family planning needs,

- have a comprehensive health history (including social, obstetric, gynecological, contraceptive, medical, STD, family and other health factors history) taken,

- have a physical examination ( including general appearance, anemia and jaundice, glands, abdomen, pelvic, weight, blood pressure) performed ,

- have a comprehensive discussion of risk factors affecting their reproductive health especially STDs and HIV/AIDS and

- be given sufficient information on the available contraceptive methods.

A detailed description of the procedures to be followed in carrying out these tasks can be found in the Family Planning Procedures Manual for Service Providers (1988) Intrah/Ministry of Health, Gaborone, Botswana and the Botswana Family Planning General Policy Guidelines and Service Standards (September revised 1994) Maternal and Child Health/Family Planning Department of Primary Health Care, Ministry of Health, Gaborone, Botswana.

For those tasks that the staff are expected to carry out for both the new and revisit family planning clients the performance of all the 38 staff observed was used to judge the cohort's performance. Using the same decision rules the cohort was judged as performing poorly when more than 13 staff did not carry out the expected tasks for the clients $(\alpha=0.036$ and $\beta=0.012)$.

The $\mathrm{MCH} / \mathrm{FP}$ unit was interested in knowing whether those staff who were observed performing the different tasks were doing so according to the service provider guidelines. For each task the number of staff performing poorly needed to judge the cohort was determined using the total number of staff observed performing the task , upper and lower thresholds of $80 \%$ and $50 \%$, respectively, and $\alpha$ and $\beta$ errors of up-to $5 \%$ each.

\section{iii) Field testing the rapid assessment mechanism}

The Zonal Supervisors and other members of the TRG are expected to undertake regular supervisory visits to all facilities where the BOTSPA trainees are providing services. The MCH/FP Unit wanted to test the feasibility of having members of the TRG undertake these visits using the new rapid assessment mechanism and the new program performance indicators. Therefore, 15 members 
of the TRG including the four Zonal Supervisors were invited to participate in this exercise.

A five day training workshop was organized to update the TRG members on current concepts in quality of care and frameworks for reproductive health program assessment, supervision and monitoring. They were then introduced to the rapid assessment mechanism, the checklists to be used in collecting information on the indicators and were trained in using the pre-tested checklists in a clinic setting.

Field testing was carried out in 25 health facilities located in 11 health districts. Thirty-eight service providers trained through BOTSPA were interviewed and observed for an average of 4 times each while providing services to family planning clients and those seeking STI services. Altogether, 164 provider-client interactions were observed, of which 39 were new family planning clients, 116 were repeat family planning clients and 9 were seeking STD services.

All 164 clients were interviewed about their experiences during the consultation, their contraceptive practices and knowledge of STIs including HIV/AIDS. On average, it took two days to assess each health facility and staff, including travel time, and monitoring and evaluation of staff performance using the checklists. The results from the field test are presented in following sections. 


\section{Results}

\section{i) Readiness of facilities to provide quality services}

Data were collected on infrastructure, availability of basic equipment and supplies, infection control procedures, management information systems, availability of IEC materials, and accessibility of services. Several items were used to assess the level of preparedness for each indicator. Every facility was assigned a pass (P) or fail (F) on each indicator by a trained observer using a pretested checklist.

Physical infrastructure: As given in Table 1, five items were used to assess the readiness of the physical infrastructure. Except for the presence of a separate counseling/examination room, fewer than eight facilities scored a fail on any of the items used to assess the infrastructure. Using the decision rules described above, the interpretation is that more than 80 percent of the facilities in this cohort (i.e. those having BOTSPA trained staff) have most of the basic infrastructure required to provide family planning and STI services, although fewer than 50 percent of the facilities have separate counseling/examination rooms.

\section{Table 1. Availability of basic infrastructure for providing family planning and STI services}

\begin{tabular}{|l|c|c|c|}
\multicolumn{1}{|c}{ ITEMS } & \multicolumn{1}{c}{$\begin{array}{c}\text { Number of } \\
\text { facilities } \\
\text { passing }\end{array}$} & $\begin{array}{c}\text { Number of } \\
\text { facilities } \\
\text { failing }\end{array}$ & $\begin{array}{c}\text { Classification of } \\
\text { cohort }\end{array}$ \\
\hline 1. Working toilet for clients & 25 & 0 & $\mathrm{P}$ \\
2. Functioning water source on compound & 25 & 0 & $\mathrm{P}$ \\
3. Functioning source of energy & 22 & 3 & $\mathrm{P}$ \\
4. Shelter for waiting clients & 21 & 4 & $\mathrm{P}$ \\
5. Separate counseling / examination room & 15 & 10 & $\mathrm{~F}$ \\
\hline
\end{tabular}

Equipment supplies and infection control: The revised Botswana Family Planning General Policy Guidelines and Service Standards manual (1994) lists the equipment and supplies that a health facility should have if it is going to provide basic family planning services: adult weighing scales, blood pressure measuring machines, stethoscope, examination couch, speculum, tenacula and a source of light. The manual also lists antiseptic lotion, needles/syringes, gloves and swabs (gauze, cotton wool) as essential supplies. The equipment and supplies required to provide good quality STD services are the same as those required for family planning services. Therefore clinics do not keep separate equipment and supplies for managing STDs.

Infection control is a major consideration when providing family planning and STI services. The availability of pit/incineration facilities, dustbin and a sharps disposal container were used to assess the readiness of a health facility to enable its staff to practice good infection control procedures. 
Fewer than eight facilities were assigned a fail for any of the equipment, supplies and the infection control items (Table 2) and so, according to the decision rules, this suggests that more than 80 percent of facilities do have the equipment, supplies and infection control facilities required to provide quality family planning and STI services. Therefore, the data show that clinics with BOTSPA trainees have adequate supplies, equipment and infection control facilities to provide good quality family planning and STI services.

\section{Table 2. Availability of basic equipment, supplies and infection control facilities}

\begin{tabular}{|c|c|c|c|}
\hline ITEMS & $\begin{array}{c}\text { Number of } \\
\text { facilities } \\
\text { passing }\end{array}$ & $\begin{array}{c}\text { Number of } \\
\text { facilities } \\
\text { failing }\end{array}$ & $\begin{array}{c}\text { Classification of } \\
\text { cohort }\end{array}$ \\
\hline \multicolumn{4}{|l|}{ Availability of basic equipment } \\
\hline $\begin{array}{l}\text { 1. Adult weighing scales } \\
\text { 2. Source of examining light } \\
\text { 3. Blood pressure machine } \\
\text { 4. Examining couch } \\
\text { 5. Stethoscope } \\
\text { 6. Speculum } \\
\text { 7. Tenaculum }\end{array}$ & $\begin{array}{l}22 \\
21 \\
25 \\
25 \\
24 \\
25 \\
19\end{array}$ & $\begin{array}{l}3 \\
4 \\
0 \\
0 \\
1 \\
0 \\
6\end{array}$ & $\begin{array}{l}\mathrm{P} \\
\mathrm{P} \\
\mathrm{P} \\
\mathrm{P} \\
\mathrm{P} \\
\mathrm{p} \\
\mathrm{P}\end{array}$ \\
\hline \multicolumn{4}{|l|}{ Availability of basic supplies } \\
\hline $\begin{array}{l}\text { 9. Antiseptic lotion } \\
\text { 10. Needles and syringes } \\
\text { 11. Disposable gloves } \\
\text { 12. Swabs/gauze and cotton wool }\end{array}$ & $\begin{array}{l}23 \\
24 \\
23 \\
24\end{array}$ & $\begin{array}{l}2 \\
1 \\
2 \\
1\end{array}$ & $\begin{array}{l}\mathrm{P} \\
\mathrm{P} \\
\mathrm{P} \\
\mathrm{P}\end{array}$ \\
\hline \multicolumn{4}{|c|}{ Availability of infection control facilities } \\
\hline $\begin{array}{l}\text { 13. Pit or incineration facilities } \\
\text { 14. Dustbin } \\
\text { 15. Sharps disposal }\end{array}$ & $\begin{array}{l}21 \\
22 \\
22\end{array}$ & $\begin{array}{l}4 \\
3 \\
3\end{array}$ & $\begin{array}{l}\mathrm{P} \\
\mathrm{P} \\
\mathrm{P}\end{array}$ \\
\hline
\end{tabular}

MIS and commodity logistics: The MCH/FP Units at health facilities keep a daily tally sheet, drug/commodity store book, monthly summary sheet, family planning register, antenatal and postnatal registers. The BOTSPA training prepared nurses to complete all these registers, and to carry out basic analyses and interpretation of data recorded. These records were examined to find out if they were well completed, legible and the information was up-to-date. A facility was assigned a pass for each of these records if the record satisfied all three items.

Fewer than eight facilities failed on the status of the daily tally sheets and monthly summary forms (Table 3); however, more than eight facilities failed on the status of the other registers. Consequently, it was concluded that the MIS needed improvement in terms of drug/commodity, family planning, antenatal and postnatal registers.

The MOH recommends that each facility should have a stock of contraceptive methods to last two to three months to avoid shortages and overstocking. The same procurement procedures 
are used for obtaining family planning methods and the drugs used to treat ailments including STIs. Availability of an adequate stock of each of the common contraceptive methods was used to assess commodity logistics. Except for the low dose combined oral contraceptive pill, fewer than eight facilities were found to have inadequate stocks of other common contraceptive methods, and so, overall, more than 80 percent of the facilities were judged to have adequate contraceptive supplies.

\section{Table 3. MIS and Commodity Logistics}

\begin{tabular}{|c|c|c|c|}
\hline ITEMS & $\begin{array}{c}\text { Number of facilities } \\
\text { passing }\end{array}$ & $\begin{array}{c}\text { Number of } \\
\text { facilities failing }\end{array}$ & $\begin{array}{c}\text { Classification of } \\
\text { cohort }\end{array}$ \\
\hline \multicolumn{4}{|c|}{ MIS (well completed data collection forms) } \\
\hline $\begin{array}{l}\text { 1.Tally sheets } \\
\text { 2. Monthly summary (MH1049) } \\
\text { 3. Drug store book } \\
\text { 4. Child welfare clinic register } \\
\text { 5. Family planning register } \\
\text { 6. ANC/PNC register }\end{array}$ & $\begin{array}{l}19 \\
22 \\
12 \\
15 \\
14 \\
14\end{array}$ & $\begin{array}{c}6 \\
3 \\
13 \\
10 \\
11 \\
11\end{array}$ & $\begin{array}{l}\mathrm{P} \\
\mathrm{P} \\
\mathrm{F} \\
\mathrm{F} \\
\mathrm{F} \\
\mathrm{F}\end{array}$ \\
\hline \multicolumn{4}{|c|}{ Logistics (availability of contraceptive methods) } \\
\hline $\begin{array}{l}\text { 7. High COC } \\
\text { 8. POP } \\
\text { 9. IUD } \\
\text { 10. DMPA } \\
\text { 11. Condoms } \\
\text { 12. Low COC }\end{array}$ & $\begin{array}{l}20 \\
21 \\
21 \\
20 \\
19 \\
17\end{array}$ & $\begin{array}{l}5 \\
4 \\
4 \\
5 \\
6 \\
8\end{array}$ & $\begin{array}{l}P \\
P \\
P \\
P \\
P \\
F\end{array}$ \\
\hline
\end{tabular}

The drugs for treating STDs are kept by the pharmacy within the clinic. Although nurses in the $\mathrm{MCH} / \mathrm{FP}$ unit prescribe the STD drugs clients have to go to the pharmacy to fill the prescription. The pharmacies do not keep separate drugs for STDs. Although this study did not examine the availability of STD drugs, results from a Situation Analysis Study carried out in 186 facilities a year before had found that $18.5 \%, 9.6 \%, 10 \%$ and $9 \%$ of clinics had experienced a stock out of first line drugs for treating gonorrhea, candida, syphilis and lower abdominal pain, respectively, at least once in the six months preceding the study. Data from the Situation Analysis suggest that future assessments should include reviews of the availability of drugs for treating STIs.

IEC materials: One objective of the BOTSPA II project was to train staff in the use of IEC materials and ensure their availability at health facilities. Therefore, the availability of flip-charts on family planning, antenatal/postnatal services, HIV/AIDS and STIs was used to determine facility readiness to undertake IEC activities. More than eight facilities were found to lack flip-charts for all of these services (Table 4). It was concluded, therefore, that less than 50 percent of the facilities have flip-charts on family planning, antenatal/postnatal, HIV/AIDS and STIs and so facilities are not well prepared to carry out IEC activities. 


\section{Table 4. Availability of flip-charts}

\begin{tabular}{|l|c|c|c|}
\hline \multicolumn{1}{|c}{ ITEMS } & $\begin{array}{c}\text { Number of facilities } \\
\text { passing }\end{array}$ & $\begin{array}{c}\text { Number of facilities } \\
\text { failing }\end{array}$ & Classification of cohort \\
\hline 1. Family planning & 8 & 17 & $\mathrm{~F}$ \\
2. ANC/PNC & 7 & 18 & $\mathrm{~F}$ \\
3. HIV/AIDS & 3 & 22 & $\mathrm{~F}$ \\
4. STIs & 4 & 21 & $\mathrm{~F}$ \\
\hline
\end{tabular}

Accessibility to services: Officially, MCH/FP, STI, and HIV/AIDS services are available to clients from 7.30 a.m. to 4.30 p.m. with a one hour break for lunch. Accessibility to services was considered poor (i.e. the facility registered a fail) if staff were observed not to be providing these services after 1.45 p.m. The presence of a sign announcing the availability of the different services was a second indicator used to assess accessibility. Facilities were assigned a fail if they did not have a sign for a particular service. More than eight facilities scored a fail on each of these items (Table 5) and so the interpretation is that fewer than 50 percent of the facilities were facilitating accessibility to $\mathrm{MCH}$, family planning and STI services.

\section{Table 5. Accessibility of MCH/FP services}

\begin{tabular}{|l|c|c|c|}
\multicolumn{1}{|c}{ ITEMS } & \multicolumn{1}{c}{$\begin{array}{c}\text { Number of } \\
\text { facilities passing }\end{array}$} & $\begin{array}{c}\text { Number of } \\
\text { facilities failing }\end{array}$ & $\begin{array}{c}\text { Classificat } \\
\text { ion of } \\
\text { cohort }\end{array}$ \\
\hline 1. Availability of sign announcing STI services & 5 & 20 & $\mathrm{~F}$ \\
2. Availability of sign announcing HIV services & 3 & 22 & $\mathrm{~F}$ \\
3. Availability of sign announcing FP services & 8 & 17 & $\mathrm{~F}$ \\
4. Availability of sign announcing ANC services & 9 & 16 & $\mathrm{~F}$ \\
5. ANC services available after 1.45 PM & 11 & 14 & $\mathrm{~F}$ \\
6. STI services available after 1.45 PM & 14 & 11 & $\mathrm{~F}$ \\
7. FP services available after 1.45 PM & 14 & 11 & $\mathrm{~F}$ \\
\hline
\end{tabular}




\section{ii) Quality of services provided}

Clinical assessment: A full clinical assessment consists of taking a medical history, measuring blood pressure and weight, performing a general physical examination, a breast examination, and a pelvic examination. For the 164 consultations observed, the proportion of clients observed to have these procedures performed were ${ }^{11}$ :

\begin{tabular}{lcc} 
Clinical assessment item & & $\%$ of consultations $(\mathrm{n}=164)$ \\
\cline { 2 - 3 } blood pressure & & $88 \%$ \\
weight & $88 \%$ \\
medical history & $76 \%$ \\
pelvic examination & \\
general physical & $53 \%$. \\
breast examination & $49 \%$ \\
& $45 \%$
\end{tabular}

Staff performance was judged by observing them perform clinical assessment procedures, STI/HIV risk assessment and counseling. The BOTSPA training manual, Family Planning Procedures Manual for Service Providers (1988) Intrah/Ministry of Health, Gaborone Botswana and the Botswana Family Planning General Policy Guidelines and Service Standards (September revised 1994) Maternal and Child Health/Family Planning Department of Primary Health Care outline the procedures to be undertaken for clients receiving family planning services at the Ministry of Health clinics ${ }^{12}$. If a service provider did not perform a procedure that is recommended for the clients whose consultations were observed the provider was assigned a fail and a pass if they performed the procedure for all clients. The guidelines recommend that all new family planning clients accepting to use medical contraceptive methods ${ }^{13}$ should have their blood pressure and weight measured, general, breast and pelvic examinations carried out, risk assessment and counseling on STDs and HIV/AIDS undertaken. The guidelines recommend that STD risk assessment and counseling be undertaken following the National AIDS Control Program (NACP) STI management guidelines. The NACP recommends that a health education or counseling session ${ }^{14}$ should include reinforcing clients knowledge, discussing fears and worries and discussion of:

- $\quad$ the importance of avoiding having sex with many partners

- $\quad$ the role of the condom in preventing STDs and HIV/AIDS

- $\quad$ importance of partner notification and treatment

- $\quad$ complications of untreated STDs

- $\quad$ importance of early diagnosis and treatment of STDs

11 New and restart family planning clients were more likely to have these procedures performed compared with repeat clients.

12 See op cit. Procedure Manual

13 According to the guidelines medical methods include pills, IUD, Depo-Provera, Norplant ${ }^{\circledR}$ and surgical methods

14 The Management of Sexually transmitted diseases in Botswana: A manual for Health Workers (1992). National AIDS Control Program (NACP), Ministry of Health, Gaborone, Botswana 
- the need for completing prescribed courses of treatment and

- the ineffectiveness of prophylactic antibiotics.

In this study 25 staff were observed providing services to 39 new family planning clients all of whom accepted to use medical methods (Pills 19, IUCD 14 and Depo-Provera 16). The performance of these staff was used to judge the cohort. Staff were assigned a fail if they did not carry out a procedure recommended by the guidelines for all the new family planning clients they were observed providing services to. The cohort was judged as not following the guidelines when more than 8 staff were assigned a fail for any of the above procedures.

\section{Table 6. Provider performance in assessing/counseling new family Planning clients}

\begin{tabular}{|l|c|c|c|}
\multicolumn{1}{|c}{ TASK } & \multicolumn{1}{c}{$\begin{array}{c}\text { No. of stafi } \\
\text { performing task }\end{array}$} & $\begin{array}{c}\text { No. not } \\
\text { performing task }\end{array}$ & $\begin{array}{c}\text { Classification of } \\
\text { cohort }\end{array}$ \\
\hline 1. Measuring Blood Pressure & 22 & 3 & $\mathrm{P}$ \\
2. Measuring Weight & 23 & 2 & $\mathrm{P}$ \\
3. Carrying General Examination & 20 & 5 & $\mathrm{P}$ \\
4. Performing Breast Examination & 20 & 5 & $\mathrm{P}$ \\
5. Performing Pelvic Examination & 22 & 3 & $\mathrm{P}$ \\
6. Carrying out STD risk Assessment & 10 & 15 & $\mathrm{~F}$ \\
7. Carrying STD/AIDS Counseling & 15 & 10 & $\mathrm{~F}$ \\
\hline
\end{tabular}

The cohort performed well as far as examining new clients was concerned. Fewer than 8 staff in the sample observed did not assess new family planning clients according to the guidelines. This result is interpreted to mean that at least $80 \%$ of the BOTSPA trainees do assess new family planning clients following the available guidelines. The finding that more than 8 of the staff observed did not carry out STD risk assessment and counseling for the new clients they provided services to means that fewer than $50 \%$ of the BOTSPA trainees carry out these tasks for new clients.

All revisit clients are expected to be assessed for risk factors to STDs and HIV/AIDS and counseled at each clinic visit. Thirty six staff were observed providing services to 116 revisit clients during this study. Using the same thresholds and $\beta$ and $\alpha$ errors the cohort was judged as not following the guidelines for these tasks when more than 11staff were observed not to carry them out for the revisit clients. During the study more than 11 staff did not carry out these tasks during the consultations observed for the revisit clients. It was therefore concluded that less than $50 \%$ of staff in the cohort of BOTSPA trainees carry out STD/AIDS risk assessment and counseling for revisit clients as required by the $\mathrm{MCH} / \mathrm{FP}$ unit. The findings suggest that the $\mathrm{MCH} / \mathrm{FP}$ unit needs to emphasize the importance of STD and HIV/AIDS risk assessment and counseling for both new and revisit family planning clients during training and supervision visits.

To assess the clinical skills of the cohort, a trained observer used a checklist prepared from the Family Planning Procedures Manual for Service Providers (1988) Intrah/Ministry of Health, 
Gaborone Botswana and the Botswana Family Planning General Policy Guidelines. The checklist was used to record how the staff were measuring blood pressure, weight, carrying out general , breast and pelvic examinations for the clients. The manual details the steps to be followed when undertaking these procedures for clients. The number of staff observed performing these procedures for both new and revisit clients ranged between 25 and 37 which is well above the minimum of 16 required to make any judgment about the performance of the cohort. The decision rules of an upper and lower threshold of $80 \%$ and $50 \%$, respectively, and $\beta$ and $\alpha$ errors not exceeding 5\% each were used to determine the maximum number of failures allowed to occur in the sample of staff observed performing the different procedures before the cohort can be judged as performing poorly.

Thirty-four staff were observed measuring blood pressure and weight, 31 were observed performing a general and pelvic examination, and 29 were observed performing breast examinations. Judgment of the performance of the cohort involved first assigning each staff member a pass or fail according to whether or not they performed a procedure following the key steps outlined in the manual. Thereafter, the total number of staff scoring a pass or fail was used to judge how the cohort had performed for each procedure. Table 7 shows the maximum number of staff allowed to fail on each procedure in the sample for the cohort to still be considered as performing well on that procedure. The number of staff observed to have failed on each procedure in this study is also shown and whenever this number exceeds the maximum number of failures allowed in the sample the cohort was judged as having performed poorly for that procedure.

Overall, the cohort passed on 3 of the 5 procedures used to assess new family planning clients. However, the cohort failed on three of the six items for general examination, three of the four for breast examinations and one of the four for pelvic assessment. These results suggest that the cohort needs improvement in general and breast examination procedures (Table 7).

Although providers performed speculum and bi-manual examinations as part of the pelvic examination, they failed on some important aspects of these procedures. For example, they did not examine the speculum for nature of discharge on withdrawing it from the genital tract and did not palpate the adenexia for masses and/or tenderness. These are important steps when detecting and diagnosing STIs using the syndromic approach (Data not shown on table). 
Table 7. Cohort performance during clinical assessment of clients

\begin{tabular}{|c|c|c|c|}
\hline ITEMS & $\begin{array}{c}\text { Maximum } \\
\text { number failures allowed in } \\
\text { sample }\end{array}$ & $\begin{array}{c}\text { Number of } \\
\text { Observed } \\
\text { failures }\end{array}$ & Classification of cohort \\
\hline \multicolumn{4}{|l|}{ Measuring Blood Pressure $(\mathrm{N}=34)$} \\
\hline $\begin{array}{l}\text { 1. Applies cuff correctly } \\
\text { 2. Places stethoscope correctly }\end{array}$ & $\begin{array}{l}11 \\
11\end{array}$ & $\begin{array}{l}4 \\
7\end{array}$ & $\begin{array}{l}\mathrm{P} \\
\mathrm{P}\end{array}$ \\
\hline \multicolumn{4}{|l|}{ Measuring Weight $(\mathrm{N}=34)$} \\
\hline $\begin{array}{l}\text { 3. Asks client to remove excess } \\
\text { clothing } \\
\text { 4. Asks client to stand on scale } \\
\text { without support }\end{array}$ & $\begin{array}{l}11 \\
11\end{array}$ & $\begin{array}{l}6 \\
5\end{array}$ & $\begin{array}{l}\mathrm{P} \\
\mathrm{P}\end{array}$ \\
\hline \multicolumn{4}{|l|}{ General Examination $(\mathrm{N}=31)$} \\
\hline $\begin{array}{l}\text { 5. Checks for anemia } \\
\text { 6. Palpates abdomen } \\
\text { 7. Checks for varicose veins } \\
\text { 8. Checks skin for color } \\
\text { changes } \\
\text { 9. Auscultate chest } \\
\text { 10. Check for lymphnodes }\end{array}$ & $\begin{array}{l}10 \\
10 \\
10 \\
10 \\
10 \\
10\end{array}$ & $\begin{array}{c}7 \\
6 \\
9 \\
19 \\
19 \\
17\end{array}$ & $\begin{array}{l}\mathrm{P} \\
\mathrm{P} \\
\mathrm{P} \\
\mathrm{F} \\
\mathrm{F} \\
\mathrm{F}\end{array}$ \\
\hline \multicolumn{4}{|l|}{ Breast Examination $(\mathrm{N}=29)$} \\
\hline $\begin{array}{l}\text { 11. Palpates all four breast } \\
\text { quadrants } \\
\text { 12. Asks client to raise arms } \\
\text { above head } \\
\text { 13. Squeezes nipples to check } \\
\text { secretions } \\
\text { 14. Examines axilla for lymph } \\
\text { nodes }\end{array}$ & $\begin{array}{l}9 \\
9 \\
9 \\
9\end{array}$ & $\begin{array}{l}1 \\
15 \\
14 \\
15\end{array}$ & $\begin{array}{l}\mathrm{P} \\
\mathrm{F} \\
\mathrm{F} \\
\mathrm{F}\end{array}$ \\
\hline \multicolumn{4}{|l|}{ Pelvic Examination $(\mathrm{N}=31)$} \\
\hline $\begin{array}{l}\text { 15. Separates labia when } \\
\text { inspecting genitalia } \\
\text { 16. Performs speculum } \\
\text { examination } \\
\text { 17. Performs bi-manual } \\
\text { examination } \\
\text { 18. Explains procedure to } \\
\text { client }\end{array}$ & $\begin{array}{l}10 \\
10 \\
10 \\
10\end{array}$ & $\begin{array}{l}8 \\
2 \\
8 \\
10\end{array}$ & $\begin{array}{l}\mathrm{P} \\
\mathrm{P} \\
\mathrm{P} \\
\mathrm{P}\end{array}$ \\
\hline
\end{tabular}


STI/HIV risk assessment: One of the key elements of the integrated approach as implemented in Botswana is that a provider is expected to undertake a risk assessment with all new and revisit family planning clients at all clinic visits. The program believes that a client's risk status changes all the time therefore it is important to review the risk status for revisit clients at each clinic visit. During the 164 consultations observed, however, staff carried out a risk assessment for 57 clients. As noted earlier, few staff were carrying out some form of STI/HIV risk assessment for their clients. According to the guidelines for the integrated approach introduced through the BOTSPA Project, five characteristics are recommended for use during STD and HIV/AIDS risk assessment. However, these were not uniformly asked about in all 57 consultations which included a risk assessment, i.e.:

\section{$\underline{\text { Risk assessment item }}$}

Client's concerns about STI/HIV

Past history of symptoms suggestive of STIs/HIV in client

Partner's residence

Number of sexual partners in the past 12 months
\% of risk assessments $(\mathrm{n}=57)$

$61 \%$

$59 \%$

$32 \%$

$26 \%$

Past history of symptoms suggestive of STIs/HIV in client's partner(s) $18 \%$

To judge providers' skills in STD and HIV/AIDS risk assessment, each provider was assigned a pass when he/she asked clients about each of the risk factors during the observed consultation and scored a fail if they did not do so. The number of staff scoring a pass or fail was then summed and used to judge the performance of the cohort for each of the risk factors. The cohort was considered as having failed on a particular risk factor if eight or more staff did not inquire about it during any of the consultations observed (Table 8). The results show that except for inquiring about previous symptoms of STD in the client, fewer than $80 \%$ of the cohort of BOTSPA trainees were asking clients about any of the suggested STD and HIV/AIDS risk factors. This finding suggests that the $\mathrm{MOH}$ needs to put a lot of emphasis during training and supervisory visits on ensuring that risk assessments are undertaken routinely in the future.

\section{Table 8: $\quad$ Provider performance for STI/HIV risk assessment}

\begin{tabular}{|l|c|c|c|}
\multicolumn{1}{|c}{ ITEM } & $\begin{array}{c}\text { Number of staff } \\
\text { passing }\end{array}$ & $\begin{array}{c}\text { Number of } \\
\text { staff failing }\end{array}$ & $\begin{array}{c}\text { Classification } \\
\text { of cohort }\end{array}$ \\
\hline 1. Ask about previous symptoms in client & 17 & 8 & $\mathrm{P}$ \\
2. Ask about partners in past 12 months & 11 & 24 & $\mathrm{~F}$ \\
3. Ask about clients concerns about STI/HIV & 16 & 9 & $\mathrm{~F}$ \\
4. Ask about previous/current symptoms in partner & 7 & 18 & $\mathrm{~F}$ \\
5. Ask about partners residence & 13 & 12 & $\mathrm{~F}$ \\
\hline
\end{tabular}


STI/HIV Counseling: Overall 87 clients were observed to be counseled about STIs and HIV/AIDS during the 164 consultations. The quality of counseling provided to clients was judged by the proportion of clients counseled who had been informed about the following items:

Counseling item

Condom use

Reducing number of sex partners

Signs and symptoms of STIs

Complications from STIs

Proper treatment in managing STIs

Partner notification
$\%$ of consultations $(\mathrm{n}=87)$

$97 \%$
$51 \%$
$30 \%$
$16 \%$
$15 \%$
$13 \%$

$97 \%$

$30 \%$.

$15 \%$

$13 \%$

These results show that client counseling currently emphasizes only the reduction in number of sex partners and condom use. The data also show that although more than $50 \%$ of clients were counseled about STIs and HIV/AIDS, the topics varied greatly between the clients.

The counseling skills for the cohort were assessed based on the 33 providers observed providing STD and HIV/AIDS counseling to clients. Using a lower and upper thresh-hold of 50\% and $80 \%$, respectively, and $\beta$ and $\alpha$ errors not exceeding 5\% each it was determined that for the cohort to pass on any of these counseling items ten or fewer failures were acceptable in a sample of 33 providers. Using the above decision rule the cohort passed on only two of the six items (Table 9). These findings suggest that the providers require considerable improvement in counseling skills, although it was encouraging to note that most providers counseled clients about condom use and minimizing the number of sexual partners, both important preventive measures.

\section{Table 9. Provider performance on STI/HIV counseling}

\begin{tabular}{|c|c|c|c|}
\hline ITEM & $\begin{array}{c}\text { Number of staff } \\
\text { passing }\end{array}$ & $\begin{array}{c}\text { Number of staff } \\
\text { failing }\end{array}$ & $\begin{array}{c}\text { Classification of } \\
\text { cohort }\end{array}$ \\
\hline 1. Mentions number of sexual partners & 23 & 10 & $\mathrm{P}$ \\
\hline 2. Mentions condom use & 33 & 0 & $\mathrm{P}$ \\
\hline 3. Mentions importance of partner notification & 9 & 24 & $\mathrm{~F}$ \\
\hline 4. Mentions importance of proper treatment & 9 & 24 & $\mathrm{~F}$ \\
\hline 5. Mentions complications & 12 & 21 & $\mathrm{~F}$ \\
\hline 6. Mentions symptoms and signs & 14 & 19 & $\mathrm{~F}$ \\
\hline
\end{tabular}

STI Management: Because only nine (six percent) of the 164 clients observed had symptoms and/or signs suggestive of an STI, and these were served by six different providers, it is difficult to make any meaningful judgments about individual staff skills in managing STIs.

Impact of services provided: Knowledge of symptoms of STDs and ways of protecting oneself from STDs was used to measure the impact of counseling services provided at the health facilities. Clients knowledge of symptoms and ways of protecting oneself from STDs was assessed during exit interviews. Overall knowledge of symptoms was poor and there were no differences between those women who had been counseled on STDs during the consultations and those that were not 
counseled (Table 10). However, significantly more clients who were not counseled mentioned pain on passing urine as a symptom of STDs while abnormal growths in the genital area was mentioned ,more frequently by clients who had been counseled. This result was not surprising given that the quality of counseling provided to clients was poor and has no immediate effect on clients knowledge of STD symptoms.

Table 10. Knowledge of STI symptoms among MCH/FP clients

\begin{tabular}{|l|c|c|c|}
\hline \multicolumn{2}{|c}{$\begin{array}{c}\text { \% Counseled Clients } \\
\text { Naming Symptom (N=87) }\end{array}$} & $\begin{array}{c}\text { \% Non Counseled } \\
\text { clients Naming } \\
\text { Symptom (N=77) }\end{array}$ & $\begin{array}{c}\text { Statistical Test } \\
\text { P-Value }\end{array}$ \\
\hline Genital Lesions and Ulcers & 66 & 65 & 0.931 \\
\hline Weight loss & 63 & 49 & 0.102 \\
\hline Vaginal discharge & 47 & 40 & 0.467 \\
\hline Chronic diarrhea & 44 & 46 & 0.943 \\
\hline Genital itching & 32 & 25 & 0.374 \\
\hline Pain on passing urine & 23 & 42 & 0.017 \\
\hline Abnormal Growths in Genital area & 23 & 8 & 0.014 \\
\hline Lower abdominal pain & 13 & 21 & 0.175 \\
\hline Urethral discharge in men & 10 & 4 & - \\
\hline Painful intercourse & 2 & 1 & - \\
\hline
\end{tabular}




\section{Summary of key results}

The purpose of this assessment was two-fold: to determine the readiness of health facilities in Botswana to offer quality family planning and STI management services following activities implemented under the BOTSPA Project; and to evaluate the quality of service provided by providers who had been trained through the BOTSPA Project.

Overall the mechanism was found to be generally acceptable, easy to use by staff and managers, and provided valid information on the readiness of the health facilities to provide family planning and STI services. The mechanism was also found to be useful in identifying specific areas that needed attention at both the health facility and service provider levels.

\section{i). Readiness of facilities to provide quality services:}

- Basic infrastructure is present, although attention needs to be paid to ensuring that separate counseling / examination rooms are available at all facilities to safeguard privacy during client / provider interactions.

- Basic equipment, supplies and infection control facilities are almost universally available.

- Although clinic registers and the drug store books were available at most facilities, they were not well completed, legible and did not have up-to-date information.

- Apart from the low dose combined oral contraceptive pill found to be missing at several health facilities, other commonly used contraceptive commodities were generally available.

- Flip-charts which are important for informing, educating and communicating with clients about family planning and STIs were lacking in most facilities.

- Despite the official expectation, family planning, STI and HIV/AIDS services were not being provided to clients after 1.45 p.m. Also few facilities had signs announcing the availability of family planning, STI and HIV/AIDS services at the facilities.

\section{ii). Quality of Services Provided}

- Although most of service providers were performing all the clinical procedures required for new family planning clients many were found to lack adequate skills when performing general and breast examinations, STD/AIDS risk assessment and counseling for clients

- Staff were not carrying out STD/AIDS risk assessment and counseling for clients as is required by the guidelines.

- Counseling provided by staff did not have a major impact on the knowledge of symptoms for STDs among clients 


\section{Use of results}

The MCH/FP unit has utilized this information to more accurately define areas in their program that need to be addressed. For example BOTSPA trainers have used these results to revise their training curriculum to put more emphasis on general and breast examination procedures, STD and HIV/AIDS risk assessment and counseling areas identified as requiring improvement by this exercise. The MCH/FP unit revised its family planning client record forms to facilitate the recording of information required to measure some of the indicators. The information has also been used in training workshops for supervisors in the District Health Teams and in the development of checklists for these supervisors. Many of the indicators defined in this study have also been incooperated in the Ministry of Health Information System for use at a national level. 


\section{Appendix 1 LIST OF INDICATORS}

Indicators for monitoring the performance of the MCH/FP program in Botswana: Developed at a workshop held in FrancisTown June 10-14, 1996

\section{READINESS INDICATORS}

\section{Infrastructure}

$1 \quad$ Percentage of facilities with working clients toilets

$2 \quad$ Percentage of facilities with functioning water source on the compound

$3 \quad$ Percentage of facilities with sheltered waiting areas

$4 \quad$ Percentage of facilities with separate counseling/exam room

$5 \quad$ Percentage of facilities with working source of energy

\section{Accessibility}

6 Percentage of facilities with signs announcing the availability of services at the health facility

7 Percentage of facilities that are observed to provide Reproductive Health services after 1:45 p.m.

\section{Equipment and supplies}

8 Percentage of facilities with functioning standardized basic equipment (see table)

$9 \quad$ Percentage of facilities with adequate (3 month buffer) supply of unexpired stock

\begin{tabular}{|c|c|c|c|c|}
\hline \multicolumn{2}{|l|}{ Method/Service } & Equipment & Supplies & Commodities \\
\hline \multirow[t]{5}{*}{ Methods } & $\begin{array}{l}\text { Orals } \\
\text { Condoms } \\
\text { Spermicide } \\
\end{array}$ & $\begin{array}{l}\text { BP machines } \\
\text { scales } \\
\text { stationery }\end{array}$ & & $\begin{array}{l}\text { Pills } \\
\text { Condoms } \\
\text { Spermicide } \\
\end{array}$ \\
\hline & IUCD & $\begin{array}{l}\text { Speculum } \\
\text { Tenaculum } \\
\text { Source of light } \\
\text { Couch }\end{array}$ & $\begin{array}{l}\text { Gloves } \\
\text { Cotton wool } \\
\text { Swabs/gauze }\end{array}$ & IUCD \\
\hline & Injectables & $\begin{array}{l}\text { Needles/syringes } \\
\text { (disposable) } \\
\text { Sharps container }\end{array}$ & $\begin{array}{l}\text { Cotton wool } \\
\text { Antiseptic lotion }\end{array}$ & Depo \\
\hline & Norplant & $\begin{array}{l}\text { Couch } \\
\text { Insertion kit } \\
\text { Removal kit }\end{array}$ & $\begin{array}{l}\text { Local anesthesia } \\
\text { Syringes } \\
\text { Needles }\end{array}$ & Implants \\
\hline & VSC & $\begin{array}{l}\text { Minilap kit } \\
\text { Gynecologic table } \\
\text { Source of light } \\
\text { Resuscitation tray }\end{array}$ & $\begin{array}{l}\text { Gloves } \\
\text { Local anesthesia } \\
\text { Needles/syringes } \\
\text { Sutures/needles } \\
\text { Antiseptic lotion }\end{array}$ & \\
\hline \multirow[t]{3}{*}{$\begin{array}{l}\text { Reproductive health } \\
\text { assessment }\end{array}$} & Pap smear & $\begin{array}{l}\text { Speculum } \\
\text { Couch } \\
\text { Source of light }\end{array}$ & $\begin{array}{l}\text { Spatula/brushes } \\
\text { Slides } \\
\text { Fixatives } \\
\text { Gloves } \\
\text { Antiseptic lotion }\end{array}$ & \\
\hline & Pelvic exam & $\begin{array}{l}\text { Speculum } \\
\text { Couch }\end{array}$ & $\begin{array}{l}\text { Gloves } \\
\text { Lotions } \\
\text { Swabs } \\
\text { Source of light }\end{array}$ & \\
\hline & General exam & $\begin{array}{l}\text { BP machine } \\
\text { Scales } \\
\text { Stethoscope }\end{array}$ & & \\
\hline
\end{tabular}




\section{Infection control}

10 Percentage of facilities with equipment for keeping/holding/decontaminating used medical equipment/supplies (sharps container, dustbin)

11 Percentage of facilities with well constructed, maintained and functional medical waste disposal mechanisms (pits, burning, incineration)

\section{Supervision}

12 Percentage of facilities with all planned supervision visits that have been honored

13 Percentage of supervised health facilities that received feedback (verbal or written)

\section{Management}

14 Percentage of health facilities with up-to-date guidelines, service standards, and reference manuals

15 Percentage of health facilities with who have filled all the established posts at the health facility

16 Percentage of health facilities that have experienced a stock out in last 3 months

17 Percent of facilities with well-completed data collection tools

"tools" = tally sheets, stock books, monthly summary forms, registers, FWE record book

\section{Transport and communication}

18 Percent of health facilities/institutions with a vehicle in working condition

19 Percent of facilities/institutions with a means of communication (telephone, fax, radio call)

\section{Information, Education, Communication}

20 Percentage of health facilities with poster/flip chart/pamphlet on MCH, STD/AIDS, or FP

21 Percentage of clients given any IEC material on Reproductive Health

\section{Training}

22. Percentage of staff trained in counseling, STD/HIV management, MCH, FP and IEC by type of training (i.e., pre-service, in-service, post-basic)

23. Percentage of staff trained in the past three years for each type of training

24. Percent of providers who can demonstrate skills in clinical procedures ( i.e, Taking weight, Physical exam, Breast exam, Urinalysis, History taking, IUD insertion, Pap smear collection, STD management using syndromic approach, STD risk assessment and Injection) according to stipulated guidelines and service standards.

25. Percent of providers demonstrating skills in use of visual aids during counseling (e.g. models, flip charts, booklets, posters)

\section{Orientation of new officers}

26. Percentage of health facilities that have a current standard orientation package

27. Percentage of new officers that have been oriented and have the standard orientation package

28. Percentage of facilities with current policy documents

\section{Integration}

29. Percentage of health facilities that offer MCH/FP and STD/HIV services on a daily basis

30. Percentage of health providers carrying out STD risk assessment in MCH/FP clients

31. Percentage of health providers carrying out STD counseling in MCH/FP clients

32. Percentage of health providers promoting dual methods

33. Percentage of health providers who ask or counsel STD clients about FP use

34. Percentage of clients receiving services other than the one sought for

\section{Indicators of Quality of services}

\section{Information given to clients}

35. Percentage of new clients given information on all appropriate methods available "information" = advantages, disadvantages, side effects "appropriate" = $\quad$ spacing or limiting method, depending on client's reproductive intentions

36. Percentage of new clients given information on accepted method:

Use of method

Management of side effects 


\section{Choice of methods}

37. Percentage of providers who report that they impose restrictions on methods due to age, parity, marital status, or spousal consent

Interpersonal relations

38. Percentage of clients who received a friendly welcome by the provider

39. Percentage of clients who feel were not provided with privacy

40. Percentage of clients allowed to ask questions

41. Percentage of clients satisfied with time spent receiving service at the health facility (waiting time and consultation time)

\section{Mechanisms to encourage continuity}

42. Percentage of clients who were informed of when and where to return for re-supply/checkup

\section{Services provided/received}

43. Percent of new clients who underwent blood pressure, weight, General physical exam, breast, exam, pelvic exam, STD screening, urinalysis, medical history.

\section{Impact of services provided/received}

44. Percent of clients knowledgeable on prevention of STD/HIV/AIDS

45. Percent of clients knowledgeable on signs/symptoms of STD/HIV/AIDS

46. Proportion of clients using other methods of FP who accepted condom during that visit

47. Proportion of clients who were using dual methods and still continue using

\section{Research and evaluation}

48. Percentage of planned research projects in $\mathrm{RH}$ that have been carried out

49. Percentage of projects in $\mathrm{RH}$ that have been evaluated according to plan

50. Percentage of completed research studies that have been disseminated 


\section{Appendix 2 Principles of Lot Quality Assurance Sampling}

The LQAS technique seeks to minimize the amount of data needed by using small sample sizes to determine whether specified performance thresholds have been achieved by the program. For example:

- whether a certain minimum proportion of service providers trained in a specified skill are providing quality services using the skills in which they were trained;

- whether a certain minimum proportion of facilities are prepared to deliver quality services.

The underlying principle of the LQAS is that the essence of quality control is to determine whether a specified performance threshold has been reached. By assessing whether a minimum performance standard is reached rather than measuring say the exact proportion of service providers that perform a service adequately, the binomial formula can be used to calculate the sample size. This seemingly small shift in approach to assessment has a large impact on the sample size.

LQAS uses cumulative probabilities calculated with the binomial formula to select small sample sizes and to formulate decision criteria for judging a cohort of providers or facilities. The binomial formula calculates the probability of an event occurring when the prevalence of a characteristic is known. For example, assuming that a cohort exists in which $80 \%$ of providers deliver services adequately, the binomial formula will calculate the probability that exactly 13 in a sample of 19 services providers selected from the cohort deliver services adequately. The formula is:

$$
\operatorname{Pr}_{a}=\frac{n !}{a !(n-a) !} p^{a} q^{(n-a)}
$$

Where $n=$ sample size

$\mathrm{a}=$ the number of providers who perform

$\mathrm{p}=$ the prevalence of well trained providers

$\mathrm{q}=1-\mathrm{p}$

$\operatorname{Pr}=$ the probability calculated

This formula can also be sued to calculate the probability of finding exactly how many providers retain their skills in a sample of 19. For example, the probability of finding 13 or more providers who deliver services adequately in a sample of 19 providers when the prevalence is 80 percent is obtained by calculating the cumulative probabilities of finding $\operatorname{Pr} 19+\operatorname{Pr} 18+\operatorname{Pr} 17+---$ ---- Pr 13. It is this cumulative probability that is used to determine the sample sizes, thresholds and other decision rules used in the LQAS approach.

A three part triage system is used in this approach: adequate, inadequate and very inadequate service delivery. Because the LQAS uses binomials, it can precisely identify quality at either end of this continuum i.e., adequate or very inadequate. The approach is less sensitive to measurements in between the two extremes. However, to most managers, the exact proportion of 
adequately performing providers or SDPs is less important than deciding whether the cohort has reached the desired performance threshold. Therefore, this approach enables managers to detect extremes of performance and take rational decisions on interventions. 


\title{
Appendix 3 Health facilities visited
}

\author{
AN LESOLE CLINIC \\ BOBONONG PRIMARY \\ BOSEJA CLINIC \\ DEBORAH RETIEF \\ GUMARE P. HOSPITA \\ JWANENG \\ KANYE MAIN CLINIC \\ LENTSWELETAU CLINIC \\ MAHALAPYE HOSPITAL \\ MAKALAMABEDI HP \\ MASUNGA CLINIC \\ MAUN GOV'T HOSPITAL \\ MMADINARE PRIMARY \\ MOPIPI CLINIC \\ MOSHUPA CLINIC \\ NEW TOWN CLINIC \\ PALAPYE PRIMARY HOSP \\ PANDAMATENGA CLINIC \\ PRINCESS MARINA HOSP. \\ RAMOKGONAMI CLINIC \\ S/PHIKWE GOV'T HOSP \\ SCOTTISH LIVINGSTONE \\ SELEKA CLINIC \\ SHOSHONG CLINIC \\ SOUTH EAST CLINIC
}

